\title{
TARI BARIS KEKUPU DALAM UPACARA MAMUKUR DI BANJAR LEBAH DESA ADAT SUMERTA KAJA DENPASAR
}

\author{
Oleh : \\ I Made Sudarsana \\ sudarsana@unhi.ac.id \\ UNHI Denpasar \\ Anak Agung Dwi Dirgantini \\ dwidirgantini@unhi.ac.id \\ UNHI Denpasar \\ Ida Bagus Darmayasa \\ darmayasaib@unhi.ac.id \\ UNHI Denpasar
}

\begin{abstract}
ABSTRAK
Merefleksikan unsur-unsur kesenian, khususnya seni pertunjukan, dalam ritual keagamaan, seni tari wali atau tari sakral merupakan salah satu unsur yang menunjang rangkaian segala upacara keagamaan yang ada di Bali. Artikel ini membahas salah satu tari sakral atau wali bernama Tari Baris Kekupu yang berada di Banjar Lebah Desa Adat Sumerta Kaja, Denpasar. Berdasarkan hasil penelitian, tarian ini merupakan bagian integral dari kehidupan masyarakat setempat yang selalu terikat dengan peristiwa ritual atau upacara Mamukur. Bentuk Tari Baris Kekupu, ditarikan oleh penari anak-anak perempuan karena didalam Tari Baris Kekupu ini terdapat unsur-unsur Tari Legong, Idenya terinspirasi dari hiasan kupu-kupu pada damar kurung yang dipasang saat upacara Mamukur. Selain itu, secara fungsional tarian ini dapat dipahami memiliki fungsi religius dan fungsi pelestarian budaya.
\end{abstract}

Kata Kunci: Kesenian, Tari Baris Kekupu, Upacara Mamukur

\section{ABSTRACT}

Reflecting the elements of arts, especially performance art, in religious rituals, tari wali or sacred dance is one of the elements that support a series of religious ceremonies in Bali. This article discusses one of the sacred or tari wali named Baris Kekupu Dance in Banjar Lebah Adat Sumerta Kaja Village, Denpasar. Based on research results, this dance is an integral part of the lives of local people who are always bound by ritual event called Mamukur. Form of Kekupu Line Dance, danced by female dancers because in this Baris Kekupu Dance there are elements of Legong Dance, the idea was inspired by the butterfly decoration on the damar kurung which was installed during the Mamukur ceremony. In addition, functionally this dance can be understood to have a religious function and cultural preservation function.

Keywords: Art, Baris Kekupu Dance, Mamukur Ceremony 


\section{PENDAHULUAN \\ Latar Belakang}

Agama Hindu memiliki unsurunsur rasional, ritual, emosional, dan kepercayaan. Oleh karena itu, seringkali kesenian menjadi sarana untuk memperkuat kepercayaan, hampir tidak ada upacara keagamaan yang sempurna tanpa ikut sertanya pameran atau pertunjukkan kesenian (Wicaksana, 2007:1). Seni pertunjukan di Bali merupakan khasanah budaya yang sangat terikat dengan keanekaragaman bentuk maupun tujuan. Dalam pandangan masyarakat

Bali, agama tidak sekedar kotbah dan sujud bakti, tetapi ekspresi estetis yang melibatkan jiwa atau psike.

Seni tari merupakan salah satu perwujudan dari ekspresi jiwa tersebut, yang didalamnya terkandung esensi estetis atau rasa. Menurut fungsinya seni tari dapat diklasifikasikan menjadi tiga, yaitu Wali, Bebali dan Balih-balihan. Ketiga fungsi ini diejawantahkan dalam bentuk berbagai jenis tarian yang seringkali memiliki rangkaian dengan prosesi upacara yang ada di Bali; jarang upacara di Bali yang selesai tanpa adanya kesenian, khususnya seni tari wali yang sangat erat kaitannya dalam ritual upacara. Dengan begitu, seni tari wali juga disebut sebagai tari sakral yang merupakan persembahan kepada Tuhan. Dibia (dalam Triguna 2003:97) menegaskan bahwa seni sebagai cipta, rasa, dan karsa manusia, biasanya seni sakral dikaitkan dengan upacara keagamaan sebagai wahana integral dalam upacara tersebut.

Salah satu tarian yang termasuk dalam kategori sakral adalah Tari Baris Kekupu. Tarian ini dapat dijumpai di Banjar Lebah, Desa Sumerta Kaja. Adapun ide terciptanya Tari Baris Kekupu berasal dari filosofi hiasan kupu-kupu yang terdapat pada damar kurung ('semacam lampion yang digantung di depan rumah masyarakat yang mengadakan serangkaian upacara Ngaben'). Damar kurung lebih tepatnya terdapat dalam pelaksanaan Upacara Mamukur yang merupakan simbol untuk mengingatkan dan menyadarkan roh atau jiwa seseorang yang sedang diupacarai agar dapat melepaskan diri dari ikatan-ikatan duniawi, sehingga dapat bersatu kembali dengan penciptanya (Darmini, 2008: 40-41).

Tari Baris Kekupu disamakan dengan makna dari damar kurung yaitu sebagai perwujudan Dewa menyinari perjalanan Atman yang telah lepas dari unsur Panca Maha Bhuta menuju ke Surga. Kekupu tersebut dianggap sebagai perwujudan Dewa yang akan menolong Atman dalam perjalanannya untuk mencapai moksa. Tari Baris Kekupu dianggap tari sakral oleh masyarakat pendukungnya karena pementasannya diperuntukan pada upacara keagamaan yaitu upacara Mamukur di Banjar Lebah. Berdasarkan alasan tersebut, artikel ini bertujuan memahami Tari Baris Kekupu secara lebih mendalam tanpa mengurangi makna yang sudah tertanam dalam pemahaman masyarakat.

\section{METODOLOGI}

Jenis penelitian yang digunakan adalah penelitian kualitatif. Metode penelitian kualitatif adalah metode penelitian yang berlandaskan pada paradigma pos-positivisme, digunakan untuk meneliti kondisi obyek secara alamiah, dimana peneliti adalah sebagai instrumen kunci. Pengumpulan data dilakukan dengan teknik observasi dan wawancara secara purposive dan snowball. Analisis data bersifat induktif/kualitatif. Hasil penelitian kualitatif lebih menekankan makna dari pada generalisasi (Sugiyono, 2008: 15). Teori yang digunakan untuk penelitian ini adalah teori 
fungsional struktural, ekspresi seni dan teori nilai.

\section{PEMBAHASAN TARI BARIS KEKUPU}

\subsection{Deskripsi Tari Baris Kekupu}

Tari Baris Kekupu ini menggambarkan sekelompok kupu-kupu yang sedang bermain di Taman Bunga dengan gerak lemah gemulai yang memperlihatkan keelokan warna warni dari sayapnya. Tarian ini dipentaskan dalam durasi kurang lebih 10 menit. Tari Baris Kekupu merupakan salah satu dari sekian banyak jenis Tari Baris di Bali yang ditarikan berkelompok. Pada awalnya Tari Baris Kekupu ini ditarikan oleh penari laki-laki, seperti Tari Baris pada umumnya. Kemudian digantikan oleh penari anak-anak perempuan karena didalam Tari Baris Kekupu ini terdapat unsur-unsur Tari Legong, hal ini merupakan salah satu keunikan yang terdapat pada Tari Baris Kekupu. Idenya terinspirasi dari hiasan kupu-kupu pada damar kurung yang dipasang saat upacara Mamukur, yang merupakan lambang dari Dewa yang menyinari perjalanan atma yang telah lepas dari unsur Panca Maha Bhuta menuju ke alamnya masing-masing.

Secara historis, Tari Baris Kekupu yang ada di Banjar Lebah, Desa Sumerta Kaja diciptakan sekitar tahun 1930-an oleh seorang seniman kakebyaran di Bali yang berasal dari daerah Denpasar, yaitu I Nyoman Kaler (Alm.) dan dibantu dengan I Wayan Rindi (Alm.) yang merupakan seniman sekaligus putra daerah yang berasal dari Banjar Lebah. Tari Baris Kekupu diciptakan atas dasar permintaan dari Griya Gede Lebah (sekarang bernama Griya Gede Tegal Jinga), Desa Sumerta Kaja, agar diciptakannya suatu tari wali untuk mengiringi Upacara Mamukur. Pada saat itu di Griya Gede Lebah akan melaksanakan Upacara Mamukur.

Proses penciptaan Tari Baris Kekupu berlangsung kurang lebih satu bulan yang diawali dengan proses nuasen, yaitu menentukan hari baik untuk membuat suatu karya seni khususnya seni pertunjukkan seperti Tari Baris Kekupu ini. Maka dari itulah diciptakannya Tari Baris Kekupu yang dipertunjukan pada saat upacara Mamukur atau pada umumnya disebut Nyekah, yang dipentaskan pada puncak karya Mamukur yaitu saat proses Mepurwa Daksina. Penari pertamanya adalah Ni Luh Cawan (Alm.) dan Sadri (Alm.), I Wayan Rindi (Alm.) dan salah satu Oka (anak) Ida Pedanda Griya Gede Lebah pada zaman itu juga turut serta menarikan Tari Baris Kekupu.

Ide terciptanya Tari Baris Kekupu terinspirasi dari hiasan kupu-kupu pada damar kurung yang dipasang saat Upacara Mamukur. Damar kurung merupakan simbol untuk mengingatkan atau menyadarkan roh atau jiwa seseorang yang sedang diupacarai agar dapat melepaskan ikatan-ikatan benda duniawi, sehingga dapat bersatu kembali dengan Sang Hyang Widhi Wasa. Maka dari itu Tari Baris Kekupu dipercaya sebagai perlambang Dewa yang menyinari perjalanan atma yang telah lepas dari unsur Panca Maha Bhuta menuju asalnya. Pada awalnya Tari Baris Kekupu ini ditarikan penari laki-laki, seperti Tari Baris pada umumnya. Kemudian digantikan oleh penari anak-anak perempuan hingga sekarang karena didalam Tari Baris Kekupu ini terdapat unsur-unsur tari Legong.

Berkaitan dengan eksistensi Tari Baris Kekupu, seiring dengan perkembangaannya, Tari Baris Kekupu ini pun jarang dipentaskan, karena Upacara Mamukur di Banjar Lebah tidak dilaksanakan secara rutin, hanya ketika ada salah satu anggota keluarga di Griya Tegal Jinga yang meninggal dunia barulah Upacara Mamukur dilaksanakan, sebagai rentetan dari Upacara Palebon. Oleh karena itulah Tari Baris Kekupu sangat jarang dipentaskan sehingga penari dan segala perangkat pendukung tarian ini 
mudah tergerus oleh perkembangan zaman akibat pelaksanaannya tidak dilaksanakan secara berkesinambungan. Kemudian pada tahun 2010 bertepatan dengan diadakannya Upacara Mamukur, Ketut Arini yang merupakan seorang seniman yang ada di daerah Banjar Lebah, beliau mulai merekonstruksi Tari Baris Kekupu. Dalam perekonstruksian tari Baris Kekupu, Ni Ketut Arini tidak menemui kesulitan yang berarti, sebab pada tahun 1961 beliau sendiri pernah menarikannya dalam sebuah ritual keagamaan di tempat kediamannya tepatnya di Banjar Lebah, Desa Sumerta Kaja. Dengan penggalan-penggalan ingatan Ni Ketut Arini tentang gerakangerakan pada Tari Baris Kekupu ini, beliau mulai proses perekostruksian. Ketut Arini kemudian menggarap iringan gamelannya, juga berdasarkan rangkuman potonganpotongan ingatannya.

Setelah semua rampung barulah diadakan proses latihan yang diawali dengan upacara nuasen dan mejaya-jaya. Penari yang dipilih untuk menarikan Tari Baris Kekupu ini adalah penari anak-anak perempuan karena dianggap suci, selain itu di dalam tarian ini memiliki unsur Tari Legong yang lebih indah jika dibawakan oleh penari perempuan. Akhirnya dari kerja keras tersebut maka terciptalah Tari Baris Kekupu hasil rekonstruksi Ketut Arini, tanpa mengubah makna yang terkandung dalamnya dan dipentaskan pada Upacara Mamukur yang dilaksanakan di Griya Gede Tegal Jinga, Banjar Lebah, Desa Adat Sumerta Kaja. Tari Baris Kekupu merupakan tarian sakral yang sebelum pementasannya mengahaturkan banten peras dan penarinya matur piuning terlebih dahulu sebelum menari, memohon kepada Ida Sang Hyang Widhi Wasa agar pementasan Tari Baris Kekupu dan semua rangkaian upacara Mamukur berjalan dengan lancar. Tari Baris Kekupu dipentaskan pada upacara Mamukur saat prosesi Mepurwa Daksina. Tari ini hadir dengan kesederhanannya namun terasa menggetarkan nuansa magis.
Ni Ketut Arini juga menuturkan, demi menjaga kelestarian Tari Baris Kekupu yang merupakan khasanah budaya yang dimiliki Banjar Lebah, Tari Baris Kekupu kini ditarikan juga pada saat Upacara Piodalan di Banjar Lebah yang dilaksanakan rutin setiap satu tahun sekali. Hal ini dilakukan dengan tujuan agar keberadaan Tari Baris Kekupu tetap terjaga sehingga tidak akan terjadi kepunahan lagi akibat dari penari dan perangkat pendukungnya tergerus oleh perkembangan zaman karena jarang ditarikan. Upacara Mamukur di Banjar Lebah, Desa Sumerta Kaja tidak dilaksanakan secara rutin dengan kurun waktu tertentu, oleh karena itu Tarian ini rentan mengalami kepunahan. Dengan dipentaskannya Tari Baris Kekupu pada Upacara Piodalan di Banjar Lebah tidak akan merubah struktur dan makna dari tarian itu sendiri. Selain itu Tari Baris Kekupu tetap bisa dipelajari karena pelaksanaanya dilakukan secara berkesinambungan.

\subsection{Struktur dan Ragam Gerak Tari Baris Kekupu}

Adapun struktur tari Baris Kekupu yaitu terdiri dari Papeson, Pengawak, Pengecet dan Pekaad. Berdasarkan rangkaian ragam gerak dari Tari Baris Kekupu, maka diuraikan pula pengertian dari masing-masing ragam gerak tersebut adalah sebagai berikut:

1) Agem adalah sikap atau cara pokok berdiri dalam Tari Bali. Ada berjenisjenis agem dalam Tari Bali sesuai dengan watak dari masing-masing tokoh yaitu keras atau manis. Menurut bentuknya dalam Tari Bali dapat dibagi menjadi dua yaitu: agem kanan dan agem kiri. Agem dilakukan dengan tingkatan rendah, menengah, dan tinggi. Ditentukan oleh berat badan, misalnya, pada agem kanan berat badan akan bertumpu pada kaki kanan, sedangkan pada agem kiri berat badan bertumpu pada kaki kiri. Pada sikap agem ini kedua siku diletakkan 
sejajar dengan bahu dan tangan ditekuk ke depan dengan jari-jari tangan menghadap keatas. Menurut jenisnya agem dapat dibedakan atas: agem tari putra keras, agem tari putra manis, agem tari putri keras, agem tari putri manis Bentuk-bentuk agem ini dapat dikembangkan lagi menjadi pose-pose dari yang lebih khusus seperti nawasari dan lembu ngadeg. Dalam tari Baris Kekupu menggunakan agem yang sama seperti agem pada umumnya namun jari-jari tangan sejajar lurus kedepan karena menggunakan property sayap kupukupu pada kedua tangan.

2) Ngumbang adalah gerakan berjalan yang dilakukan dengan badan sedikit merendah (ngeed), levelnya tidak berubah dan disertai dengan gerakan kepala kekiri dan kekanan sesuai dengan hentakan kaki. Ngumbang akan membentuk lintasan-lintasan pada lantai seperti ngumbang melingkar yaitu ngumbang dengan membentuk garis melingkar, ngumbang eluk penyalin yaitu ngumbang dengan membentuk garis angka delapan pada lantai. Dalam tari Baris Kekupu gerakan ngumbang dilakukan sambil menggetarkan properti sayap kupu-kupu.

3) Ngegol gerakan pinggul yang digoyangkan kekiri dan kekanan dalam tari Bali. Ngegol dapat dilakukan sesuai dengan cepat lambatnya tempo gambelan.

4) Angsel berarti tertunda (berhenti sebentar), suatu istilah yang digunakan untuk menyebutkan perubahan dinamika pada tari. Angsel dimulai dengan gerak keras mendadak, temponya cepat, sekaligus memberikan tanda perubahan dinamika dari musik iringannya. Angsel berfungsi untuk merubah posisi dari kiri kekanan atau sebaliknya, dan juga berfungsi untuk mengajukan berakhirnya suatu tarian. Tari-tarian keras seperti Baris dan
Topeng mempunyai dua jenis angsel yaitu angsel lantang dan angsel bawak. Kedua angsel ini dapat dibedakan dari penggunaan pharase musik atau gambelan yang mengiringinya. Angsel pendek biasanya hanya mengambil satu gong, sedangkan angsel panjang bisa terdiri dari empat sampai enam kali gong. Dibeberapa daerah angsel ini juga disebut ngupak. Istilah angsel berlaku juga menyebutkan perubahan dinamika dalam gamelan.

5) Ngenjet adalah gerakan badan naik turun yang sangat cepat, dalam Tari Baris Kekupu ngenjet biasanya dilakukan sambil merubah agem yang dilanjutkan dengan nyledet.

6) Sledet adalah gerakan mata yang mana gerak-gerak ini dapat dilakukan kesamping kanan atau kiri dan merupakan ekspresi pokok dalam Tari Bali. Tanpa sledet Tari Bali tidak ekspresif sama sekali.

7) Makecos adalah gerakan melompat kekanan atau kekiri dengan posisi tangan ngagem.

8) Angkeb-angkeb adalah gerakan mengepakkan sayap dalam Tari Bali. Gerakan ini digunakan pada Tari Baris Kekupu yang menggambarkan kupukupu yang sedang hinggap disuatu tanaman dan dihempas oleh angin.

9) Nyregseg adalah gerakan kaki yang dilakukan dengan cepat yang mana berat badan akan tertumpu pada kaki kanan dan kiri silih berganti.

10) Miles adalah gerakan Tari Bali untuk merubah sikap, seperti misalnya dilakukan dari sikap tanjek kemudian dilanjutkan dengan memutar tumit kaki yang menanjak kearah dalam dan dilanjutkan dengan gerakan badan merendah sehingga lutut terbuka ke samping, kaki yang tumitnya diputar tadi diangkat kebelakang dan akhirnya kembali pada sikap tanjek.

11) Maserod adalah gerakan yg diawali dengan gerakan dorong kekanan atau kekiri dan lilanjutkan dengan gerakan 
kaki satu persatu maju posisi kaki tetap menyentuh lantai.

12) Nimpah adalah posisi berlutut dengan kaki menyilang dan salah satu kaki menyentuh lantai posisi badan agak rebah kekanan ataupun kekiri. Gerakan nimpah ini merupakan salah satu gerakan khas dalam Tari Baris Kekupu yang terdapat pada bagian pengawaknya.

13) Ngubit dan nglukun adalah suatu rangkaian gerakan tangan dibawah dada dengan badan mendorong kekanan ataupun kiri lalu memutar tangan dan berakhir dengan posisi rendah dengan tangan di samping dada. Gerakan ini biasa digunakan dalam Tari Legong, gerakan ini digunakan dalam Tari Baris Kekupu karena mengandung unsur Tari Legong.

14) Malpal adalah sebuah motif berjalan dalam Tari Bali yang langkahnya jatuh pada setiap hitungan atau ketukan. Gerakan kaki ini merupakan unsur pokok dalam Tari Baris pada umumnya.

15) Mentang laras adalah gerakan kedua tangan seperti merentangkan busur. Tangan kiri direntangkan kedepan, tangan kanan ditarik kebelakang dan

16) badan merendah. Gerakan ini pula merupakan unsur gerak Tari Legong yang terdapat pada Tari Baris Kekupu.

17) Ngelawang adalah gerakan berjalan sambil ngegol dan merebahkan badan kekanan dan kekiri.

18) Matimpuh adalah posisi duduk dengan kedua tumit kaki diduduki.

19) Nengok adalah gerakan kepala menengok sesuatu.

20) Nolih kampid adalah gerakan melihat sayap yang dilakukan setelah gerakan nengok.

21) Makipekan adalah gerakan memalingkan muka atau menoleh untuk mempertegas arah pandangan.

22) Ngotag adalah gerakan kepala kekiri dan kekanan secara cepat, pusat gerakan ada pada pangkal leher.
23) Ngeseh adalah gerakan bahu bergetar secara halus maupun keras.

24) Mekeber adalah gerakan terbang dalam Tari Baris Kekupu yang menirukan gerakan serangga kupukupu.

25) Ngalih amah adalah gerakan yang menggambarkan serangga yang mencari sari-sari makanan.

\subsection{Kostum Tari Baris Kekupu}

Tari baris ada berbagai jenis di Bali yang namanya disesuaikan dengan properti maupun kostum tari yang digunakan pada saat pementasannya. Maka dari itu nama Baris Kekupu diambil dari penggambaran properti yang digunakan oleh penari. Tari Baris Kekupu dahulu memakai properti kipas dengan menggunakan gelungan legong yang sederhana, namun kini sesuai dengan perkembangan tata rias dan kostum Tari Bali, Tari Baris Kekupu yang direkonstruksi oleh Ibu Ni Ketut Arini penarinya memakai sayap seperti kupukupu berwarna-warni dan berbinar dengan menggunakan gelungan legong disertai bancangan bunga kamboja. Dengan menggunakan kostum berumabai-umbai (awir) yang berwarna-warni melambangkan keelokan warna serangga kupu-kupu pada umumnya. Tata rias yang digunakan dalam pementasannya adalah tata rias panggung putri halus.

Adapun tata cara pemakaian kostum Tari Baris Kekupu, sebelumnya diawali dengan wajah dimake up tari Bali putri halus terlebih dahulu, menggunakan baju dan celana putih kemudian menggunakan stewel dan dilanjutkan dengan memakai awiran, lamak, sesimping, badong, tutup dada, dan keris yang dipasang pada sesimping kulit, selanjutnya pemasangan gelang kana dan gelungan legong kemudian yang terakhir adalah pemasangan properti sayap kupukupu. 


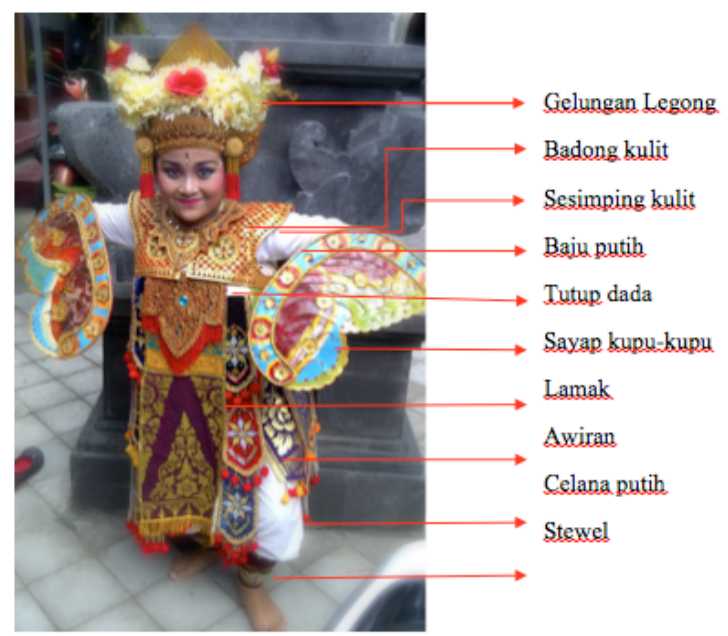

3.3 Fungsi Tari Baris Kekupu

\subsubsection{Fungsi Religius}

Tari Baris Kekupu merupakan tari sakral yang dipentaskan dalam pelaksanaan upacara Mamukur, dimana tarian ini dipentaskan pada prosesi mepurwa daksina. Makna dari mepurwa daksina adalah sebagai simbol meningkatkan status atma (roh) dari orang yang meninggal, dari status preteka manjadi Dewa Hyang atau Pitara, dan merupakan suatu proses penyucian dari atma akan menuju sumbernya yaitu Sang Hyang Paramaatma. Dengan arah perputarannya kearah kanan sebanyak tiga kali. Maknanya sebagai simbol peningkatan atau penyucian status atma kearah atas agar bisa menyatu dengan Tuhan. Dimana prosesnya dimulai dengan berputar ke kanan sebagai simbol naik, karena Ida Sang Hyang Widhi berstana diatas.

Pementasan Tari Baris Kekupu juga bertujuan untuk memotivasi dan menuntun warga Banjar Lebah untuk meningkatkan kepercayaan terhadap Tuhan beserta manifestasinya. Berdasarkan kepercayaan warga Banjar Lebah, bahwasanya Tari Baris Kekupu selain berfungsi sebagai sarana wajib dari Upacara Mamukur di Banjar Lebah, Desa Sumerta Kaja, Tari Baris Kekupu juga merupakan perwujudan Dewa yang mengiringi dan menjaga perjalanan atma yang telah lepas dari unsur Panca Maha Butha menuju Surga. Sehingga diharapkan terciptanya keseimbangan serta keselarasan hidun sesuai dengan konsen Tri Hita

diharapkán manusia dengan Sang Pencipta. Dari sudut Pawongan, diharapkan terwujudnya keseimbangan antara manusia dengan sesamanya, dan dari sudut Palemahan, dapat terwujud keselarasan antara manusia dengan lingkungannya.

\subsubsection{Fungsi Pelestarian Budaya}

Beranjak pada sistem keberagaman Umat Hindu maka tidak dapat lepas dari unsur Seni Budaya. Hal ini dikarenakan seni budaya merupakan wadah dalam melaksanakan aktifitas ritual keagamaan. Seni merupakan hasil cipta, rasa dan karsa manusia yang dituangkan melalui ide pikiran kedalam sebuah bentuk karya. Oleh karena itu, pada dasarnya manusia membutuhkan seni dalam kehidupannya, maka dari itu wajib hukumnya untuk setiap manusia memelihara dan melestarikan semua karya seni yang ada. Sehubungan dengan pelestarian kesenian terdapat sebuah seni budaya dalam Tari Baris Kekupu.

Tari Baris Kekupu memiliki fungsi sebagai pelestarian unsur budaya. Hal ini dikarenakan Tari Baris Kekupu merupakan produk budaya dari masyarakat Bali yaitu masyarakat Banjar Lebah khususnya. Selanjutnya disampaikan bahwa kesenian ini juga merupakan warisan dari leluhur yang memiliki unsur religi dalam pelaksanaan Upacara Mamukur. Maka dapat dicermati bahwa pementasan Tari Baris Kekupu merupakan suatu wahana dalam pelestarian nilai seni dan budaya yang ada di Bali dan di Banjar Lebah, Desa Sumerta Kaja khususnya. Sehingga warisan leluhur yang bernilai tinggi tersebut tidak punah kembali akibat perkembangan zaman dan terkikisnya unsur pendukung tarian tersebut. Dengan tetap dipentaskannya Tari Baris Kekupu dalam Upacara Mamukur di Banjar Lebah, 
Desa Sumerta Kaja, kedepannya mampu merangsang dan membangkitkan jiwa kebersamaan pada masyarakat khususnya generasi muda untuk tetap berlatih serta melestarikan kesenian sakral ini sehingga tetap ajeg dan lestari.

\section{PENUTUP}

Berdasarkan uraian yang telah dibahas tentang bentuk Tari Baris Kekupu, eksistensi Tari Baris Kekupu, dan nilainilai pendidikan seni tari Keagamaan Hindu yang terkandung dalam Tari Baris Kekupu maka dapat ditarik kesimpulan sebagai berikut:

1. Bentuk Tari Baris Kekupu, ditarikan oleh penari anak-anak perempuan karena didalam Tari Baris Kekupu ini terdapat unsur-unsur Tari Legong, Idenya terinspirasi dari hiasan kupukupu pada damar kurung yang dipasang saat upacara Mamukur. Selain membahas tentang bentuk Tari Baris Kekupu, maka dijabarkan pula tentang Fungsi dari Tari Baris Kekupu antara lain: a) Fungsi Keagamaan, b) Fungsi Pelestarian Budaya.
2. Berkaitan dengan eksistensi Tari Baris Kekupu, seiring dengan perkembangaannya, Tari Baris Kekupu kini ditarikan juga pada saat Upacara Piodalan di Banjar Lebah yang dilaksanakan rutin setiap satu tahun sekali. Sebab Upacara Mamukur di Banjar Lebah, Desa Sumerta Kaja tidak dilaksanakan secara rutin. Maka dari itu Tari Baris Kekupu tetap bisa dipelajari karena pelaksanaanya dilakukan secara berkesinambungan.

Berdasarkan pemahaman terhadap Tari Baris Kekupu diharapkan bahwa masyarakat Bali pada umumnya agar terus melestarikan seni budaya Bali, dan khususnya bagi seniman tari agar lebih mensosialisasikan pada masyarakat umum agar secara jelas dapat mengetahui bahwa Tari Baris Kekupu merupakan seni tari yang tergolong kedalam tari sakral yang dipentaskan pada Upacara Mamukur, dan lebih banyak membuat buku-buku yang terkait dengan Tari Baris Kekupu, agar terdapat suatu catatan-catatan yang relevan.

\section{DAFTAR PUSTAKA}

Arwati, Ni Made Sri. 1999. Upacara Upakara. Denpasar: Upada Sastra

Bandem, I Made. 1983. Ensiklopedi Tari Bali. Denpasar: Akademi Seni Tari Indonesia (ASTI).

Darmini, Ni Luh Rai. 2008. Damar Kurung Dalam Upacara Pitra Yadnya di Desa Kukuh Kecamatan Marga, Kabupaten Tabanan. Skripsi untuk mendapat gelar Sarjana S1.

Kardji, I Wayan. 2010. Serba-serbi Tari Baris. Denpasar: CV. Bali Media Adi Karsa.

Poerwadarminta, WJS. 1993. Kamus Umum Bahasa Indonesia. Jakarta: Balai Pustaka.

Prihatini. 1980. Pengantar Pengetahuan Tari. Surabaya: Paramita

Ritzer, George dan Doouglas Goodman. 2004. Teori Sosiologi Modern. Jakarta: Prenada Kencana.

Sri Arwati, Ni Made. 2007. Upacara Mamukur. Surabaya: Paramita. 
Suprayoga, Imam dan Tabroni, 2001. Metodologi Penelitian Sosial Agama. Bandung: Remaja Redakarya.

Tim Penyusun. 1981. Evolusi Tari Bali. Proyek Penggalian/Pembinaan Seni Budaya Klasik dan Baru.

Titib, I Made. 2001. Teologi dan Simbol-simbol dalam Agama Hindu. Surabaya: Paramita.

Team Survey. 1977. Pengantar Dasar Beberapa Tari. Denpasar: Akademi Seni Tari Indonesia (ASTI) 